\title{
Use of Spreadsheet for A Mixed Integer Linear Programming Model - Multi-Objective Flow Shop Scheduling With Normalisers
}

\author{
A.Maheswaran ${ }^{1}$, ML.Mahadevan ${ }^{2}$, B.Andrew Sheldon ${ }^{3}$ \\ ${ }^{1}$ P.G Scholar, Department of Mechanical Engineering, Thiagarajar College of Engineering, Madurai, \\ 625015, India.mahes.ak@yahoo.com \\ 2 Assistant Professor, Department of Mechanical Engineering, Thiagarajar College of Engineering, Madurai, \\ 625015, India.mlmmech@gmail.com \\ ${ }^{3}$ P.G Scholar, Department of Mechanical Engineering, Thiagarajar College of Engineering, Madurai, \\ 625015, India.andrewsheldon7@gmail.com
}

\begin{abstract}
Flow shop is a kind of job shop in which jobs have the similar process sequence. Flows shop scheduling problem (FSP) comes under NP (Non polynomial) hard category which means hardness of the problem will increase as much as the number of jobs increases. In FSP there will be a $n$ ! possible sequences can be formed if we take $n$ as number of jobs. Everyday flow shop will receive different set of jobs, schedulers have to make decision as quick as possible. A wrong decision in FSP may result in huge loss to the organization. Generally, most of the literatures about the flow shop are single objective but in real life single objective will not be suitable because the real world problems are multi objective in nature. Multi objective flow shop scheduling (MOFSP) is necessary to satisfy wide expectations of different people. In this study MOFSP is going to be handled and a computer based user interface model is going to be developed. A Mixed Integer Linear Programming (MILP) model also going to be formulated as per the required objectives. Comparison of single objective and multi objective problem's results are going to be analyzed and the procedure using Spreadsheet with User Friendly Interface (SUFI) going to be developed and verified.
\end{abstract}

Keywords: NP (Non polynomial) hard, Mixed Integer Linear Programming (MILP), Multi-Objective Flow Shop Scheduling (MOFSP).

\section{INTRODUCTION}

In the field of operation research, scheduling is being considered as an active field for research. It includes allocation of resources to a series of different activities over a given period of time. The scheduling problems can be defined as per the available set of jobs for processing which may need either one operation or multiple operations for completion. For each operation type, there will be one work station. Therefore, in shops with single operation jobs, there can be one station and in shops it can be with m-operations. The single station shops are single and parallel machine problems, and the multi-station shops include flow, job, and open shops. Flow shop is one of the types of job shops in which all the jobs will have same processing sequences on set of machines. This is the example for flow shop scheduling.

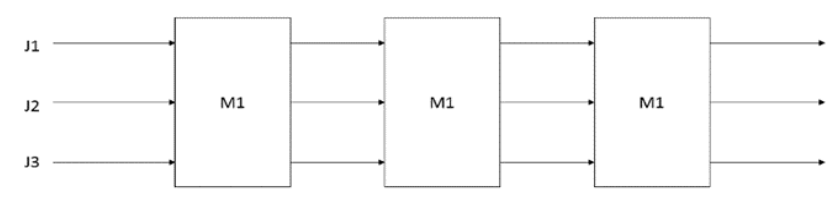

Figure 1 Flow Shop
FSP is inspired from the real world problems. So FSP should also be a multi objective because the nature of the real problems are always multi objective. Most of the literature for FSP is single objective based. So FSP has to be carried out in a multi objective way, it can be called multi objective flow shop scheduling problem (MOFSP).

There also many ways to make single objective optimisation problems into a multi objective optimisation problem like weighted objective methods and pareto approaches. Generally, multi objective means a problem which considers greater than or equal to two objectives.

There are three approaches are there to deal the optimisation problems those were classified according to the decision making process. If the decision making process take place at the starting point of work means it is called priori approach. The second approach is called posteriori in which decision making will be taken at the end of the process. And the final approach is named interactive approach decision will be taken in interactive way. For dealing multi objective problems, priori will be a better choice because in priori objectives can be weighted and combined as single objective. 


\section{International Journal of Research in Advent Technology, Vol.7, No.4, April 2019 E-ISSN: 2321-9637 \\ Available online at www.ijrat.org}

Solving process of FSP has to be as quick as possible because the particular decision will hold entire process. Because of technical advancements now a days computerized approach is being used in every step of this world. It doesn't leave FSP too. FSP can be approached as per the required results like exact method and approximation method. In exact method small size problems only can be addressed but in approximation method huge size problems can be solved.

For dealing exact method problems there are two general ways are there, one is branch and bound another one is programming models. Programming models means mathematical programming like integer programming, linear programming and mixed integer linear programming. To solve FSP in exact method Mixed integer linear programming can be used there also so many familiar models are available. Because FSP will have both continuous values and discrete values it also has binary variables too so that mixed integer linear programming is the opt one to handle FSP.

For the last 20 years multi objective optimisation got attention of researchers in operations research because of the new technological improvements along with the techniques.

This study deals the MOFSP problem with the MILP model in which total completion time and makespan are the objectives. Here exact method is going to be used as seen above. weighted objective method is used here to combine two objectives into a single objective and also normalising factors are included to avoid the domination of one objective on the other. Because a big range objective can easily dominate the low range objective to avoid this situation fuzzy membership equation going to be used here.

Comparison of single objective and multi objective results will be compared to show the efficiency of the multi objective problem. Here spreadsheet is going to be used to solve the problems the procedure to solve MOFSP is also in detail explained in this study. Advantage of using normalisers in the equation is also be showed.

\section{PROBLEM DESCRIPTION}

As stated, FSP is a NP hard problem as much as the no of jobs increases it makes scheduling a hard task for the scheduler. Generally, scheduler uses intuition, subjective scheduling it may leads to higher makespan or total completion time so they use an objective concerned way. Most of the literatures in FSP are single objective but the real world problems are not a single objective one it always has two conflicting objectives to consider. For example, we require minimum makespan it may result in higher tardiness here two conflicting objectives one is manufacturer point of view another one is customer point of view both the things have to be fulfilled so MOFSP is needed.

A computer based MOFSP solver is going to be created for FSP to help the schedulers to make quick decisions because everyday flow shop will face different job sets to produce because of that scheduling decision has to be made as quick as possible. So computer based user interface scheduling solver is going to be developed and also it is going to be verified.

\section{OBJECTIVES}

- Development of MILP for MOFSP

- Procedure to solve MOFSP in spreadsheet

- Comparison of single and multi-objective flow shop scheduling problems.

\section{METHODOLOGY}

As per dhingra (2010) flow shop scheduling can be solved in the following ways

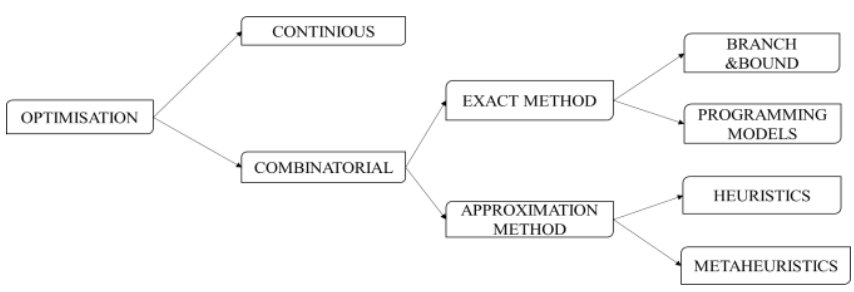

Figure 2 FSP Solving Methods

Generally, optimisation has two ways; one is known as combinatorial and another one is known is continuous. Continuous means only continuous variables will be considered, in combinatorial discrete variable will be considered along with the continuous variables. FSP addresses both continuous and discrete variables. so combinatorial approach is selected to approach the MOFSP. In that combinatorial approach there are two paths for solving FSP, one is exact method another one is approximation method.

In exact method smaller size problems only solved, to solve bigger size problems approximation methods has to be used. Approximation method classified into two types one is heuristics another one is meta heuristics. If an algorithm developed only for the particular method that is called heuristics similarly if an algorithm can be used for more than one kind of problem means it is known as meta heuristics. Exact method FSP can be solved branch and bound method or in programming models. For this study programming method is selected. 


\section{International Journal of Research in Advent Technology, Vol.7, No.4, April 2019 E-ISSN: 2321-9637 \\ Available online at www.ijrat.org}

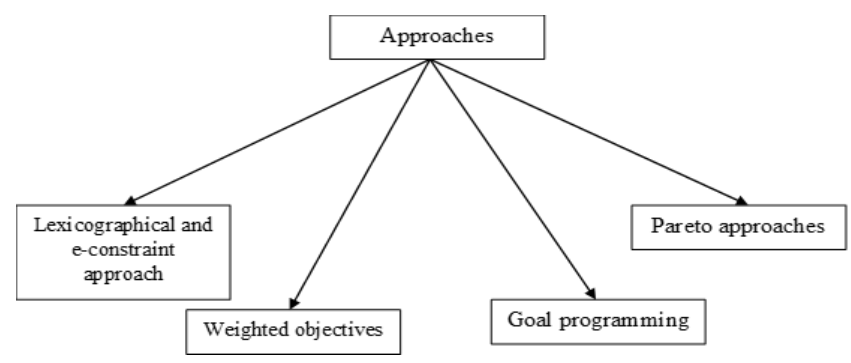

Figure 3 MOFSP Approaches

Another decision in MOFSP as per minella MOFSP can be formed in several ways like in figure 3. in that weighted objective method is going to be followed. From this weighted objective approach two individual objectives can be compiled into one objective by giving weightages to those individual objectives.

Lexicographical approach or e constraint approach means combining two individual objectives by setting targets for those individual objectives also priorities have to mentioned to clarify which is going to be done first. In this approach all objectives will have individual importance.

Pareto approach, is named posterior approach in this approach optimal value will not be considered, values nearer to the optimal value will be considered as optimal values those values will be considered as pareto lines.

Goal programming is the branch of multi-objective optimization, which is a branch of multi-criteria decision analysis (MCDA). This optimization programme can be thought of as an extension or generalisation of linear programming to handle multiple, normally conflicting objective measures. Each measures will have a goal or target value to be achieved. Unwanted deviations from this set of target values are minimised.

Here exact method is going to be carried out. The programming models MILP is selected. To convert single objective into multi objective weighted objective approach is selected. Excel solver is going to be used to solve this MOFSP.

\section{MODEL FORMULATION}

There are some MILP models already available for the FSP ronconi (2012) selected four MILP for FSP and compared it by its variable count, number of constraints and computing speed.

Table 1 Model Comparison

\begin{tabular}{|c|c|c|c|}
\hline MODEL & $\begin{array}{c}\text { BINARY } \\
\text { VARIABLE } \\
\text { S }\end{array}$ & $\begin{array}{c}\text { CONTINIOU } \\
\text { S } \\
\text { VARIABLES }\end{array}$ & $\begin{array}{c}\text { CONSTRAINT } \\
\text { S }\end{array}$ \\
\hline $\begin{array}{c}\text { WAGNE } \\
\text { R }\end{array}$ & $\mathrm{n}^{2}$ & $\mathrm{~nm}+2 \mathrm{n}-\mathrm{m}$ & $\mathrm{nm}+3 \mathrm{n}-1$ \\
\hline
\end{tabular}

\begin{tabular}{|c|c|c|c|}
\hline WILSON & $\mathrm{n}^{2}$ & $\mathrm{~nm}+3 \mathrm{n}$ & $2 \mathrm{~nm}+3 \mathrm{n}-\mathrm{m}$ \\
\hline MANNE & $\mathrm{n}(\mathrm{n}-1) / 2$ & $\mathrm{~nm}+2 \mathrm{n}$ & $\mathrm{n}^{2} \mathrm{~m}+2 \mathrm{n}$ \\
\hline LIAO & $\mathrm{n}(\mathrm{n}-1) / 2$ & $\begin{array}{c}\mathrm{n}^{2} \mathrm{~m} / 2-\mathrm{nm} / 2 \\
+2 \mathrm{n}\end{array}$ & $\begin{array}{c}\mathrm{n}^{2} \mathrm{~m} / 2+\mathrm{nm} / 2+ \\
2 \mathrm{n}\end{array}$ \\
\hline
\end{tabular}

In this four MILP models ronconi suggested Wilson and wagner models are better than other two. In this two Wilson model has lesser considering times because Wilson considers only starting time and processing time. But wagner considered idle time, wait time and processing time.

Following assumptions are made for the formulation of MILP.

- Jobs will be available at time zero.

- If a job is started it has to be completed.

- Every job has k number of operations.

- Jobs can be idle.

- Machines has to wait to get the job.

- There is no breakdown for machines.

- Machine can’t process more than one job at a time.

The MILP model is developed based on the Wilson's MILP model. The first objective is makespan that is in the equation no (1)

Minimize $\sum_{\mathrm{j}=1}^{\mathrm{n}} \mathrm{C}_{\mathrm{jm}}$

In this equation (1) Cjm denotes the completion time of a job. By adding all the completion times, we can get total completion time that is denoted in this equation

Minimize $\sum_{\mathrm{j}=1}^{\mathrm{n}} \max \left(\mathrm{C}_{\mathrm{jm}}\right)$

This equation (2) is second objective is for makespan the maximum completion time among the jobs will be taken as a makespan. Makespan is a time period to finish all the jobs within the job sets.

$C_{j m}=S_{j m}+\sum_{\mathrm{i}=1}^{\mathrm{n}} \mathrm{x}_{\mathrm{ij}} \mathrm{p}_{\mathrm{im}}$, forall $j$

Equation no (3) is completion time calculating one. By adding the starting time of a job at the last machine and the processing time on that machine completion time can be calculated

$S_{j+1, \mathrm{k}}, \geq S_{j k}+\sum_{\mathrm{i}=1}^{\mathrm{n}} \mathrm{x}_{\mathrm{ij}} \mathrm{p}_{\mathrm{ik}}$, foralljexceptnand forallk

This is (4) job constraint it refers the starting time of the current job has to be higher than the previous job's starting time and processing time.

$S_{j, \mathrm{k}+1} \geq S_{j k}+\sum_{\mathrm{i}=1}^{\mathrm{n}} \mathrm{x}_{\mathrm{ij}} \mathrm{p}_{\mathrm{ik}}$, foralljandforallkexceptm

This (5) is machine constraint which is similar to the job constraint it denotes that the starting time of the current machine has to be higher than the previous machines starting time and the processing time.

$S_{11} \geq 0$ 


\section{International Journal of Research in Advent Technology, Vol.7, No.4, April 2019 E-ISSN: 2321-9637 \\ Available online at www.ijrat.org}

Equation (6) shows that the initial value cannot be less than zero.

$\sum_{\mathrm{i}=1}^{\mathrm{n}} \mathrm{x}_{\mathrm{ij}}=1$, forall $\mathrm{j}$

$\sum_{\mathrm{i}=1}^{\mathrm{n}} \mathrm{x}_{\mathrm{ij}}=1$, foralli

These two equations (7) \& (8) are named as binary constraint which means both will have either value 1 or 0 .

$\mathrm{i}=1,2,3 \ldots . \mathrm{n}$

$\mathrm{j}=1,2,3 \ldots . . . \mathrm{n}$

$\mathrm{k}=1,2,3 \ldots . \mathrm{m}$

Here $\mathrm{i}$ means jobs, $\mathrm{j}$ means position of the jobs and $\mathrm{k}$ means machines here $\mathrm{m}$, refers the last machine in the line.

All the variables explained here

$S_{11}$ refers that the starting time of the first job in the first machine it can't be the lesser than zero.

$\mathrm{S}_{\mathrm{jk}}$ refers starting time of the $\mathrm{j}^{\text {th }}$ job at $\mathrm{k}^{\text {th }}$ machine.

$\mathrm{P}_{\mathrm{ik}}$ refers processing time of the $\mathrm{i}^{\text {th }}$ job at $\mathrm{k}^{\text {th }}$ machine.

$\mathrm{P}_{\mathrm{im}}$ refers processing time of the $\mathrm{i}^{\text {th }}$ job at last machine.

$\mathrm{C}_{\mathrm{jm}}$ refers completion time of the $\mathrm{j}^{\mathrm{th}}$ job at the last machine.

$X_{i j}$ is a binary variable if the $i^{\text {th }}$ job presents on the $j$ th position it will be 1 if not it will be zero

$\operatorname{Minimize} \sum_{j=1}^{n}\left(\frac{\mathrm{P} \alpha * C j m}{f \alpha}+\frac{\mathrm{P} \beta * \operatorname{Max}(\mathrm{C} j m)}{f \beta}\right)$

$\mathrm{P} \alpha, \mathrm{P} \beta$ are weightages

$\mathrm{f} \alpha, \mathrm{f} \beta$ are normalising factors

The reason behind normalising factors is if the weightages given is equal then higher range objective will dominate the lower range objective for example here the considered objectives are makespan and total completion time the ranges for both the objectives differs makespan range will be around 1000 means total completion time will be around 5000, Here if equal weightages given then total completion time will dominate the makespan objective to normalise these normalising factors are used. This follows fuzzy set theory

$\mu_{\mathrm{q}}\left(\mathrm{D}_{\mathrm{i}}\right)=\left\{\begin{array}{c}0 \\ \frac{f q-f q H}{f q *-f q H} \mathrm{f}_{\mathrm{q}}{ }^{\mathrm{h}} \leq \mathrm{fq} \leq \mathrm{f}_{\mathrm{q}}{ }^{*} \\ 1\end{array}\right.$

$\mathrm{f}_{\mathrm{q}}^{\mathrm{h}}$ - unacceptable value

$\mathrm{f}_{\mathrm{q}_{\mathrm{q}}}-$ value

$\mathrm{f}_{\mathrm{q}}$ - The ideal value

From this equation only normalising factors are added to the multi objective equation.

\section{ILLUSTRATOIN:}

Excel solver is going to be used for solving the data by using simplex algorithm a normal solver has a restriction of 100 constraints to solve more than that premium solver can be used.

\section{MODEL RESOLUTION IN EXCEL SPREADSHEETS}

Excel's add in solver is used here to solve 10 jobs and 4 machines. In this there are 140 decision variables in that 100 variables are binary and also 87 constraints are used to solve this problem.

For this problem data has been entered jobs in rows and machines in column from E6 to E15 for machine1 similarly for machine2, machine3, machine4 as F6 to F15, G6 to G15, H6 to H15,

From constraints to objective the how the equations are entered in the spreadsheets is going to be described here. Here binary and starting times are going to be considered as decision variables starting time variables are entered for the job 1 to job 10 like below $\mathrm{B} 6$ to $\mathrm{b} 9, \mathrm{~B} 11$ to $\mathrm{B} 14, \mathrm{~B} 16$ to $\mathrm{b} 19, \mathrm{~B} 21$ to $\mathrm{B} 24, \mathrm{~B} 26$ to $\mathrm{B} 29, \mathrm{~B} 31$ to $\mathrm{B} 34$, B36 to B39, B41 to B44, B46 to B49, B51 to B54.

First of all, binary constraints equation no (7) \& (8) is entered like below.

$\sum_{\mathrm{i}=1}^{\mathrm{n}} \mathrm{x}_{\mathrm{ij}}=1$, forallj

$\sum_{\mathrm{i}=1}^{\mathrm{n}} \mathrm{x}_{\mathrm{ij}}=1$, foralli

There are 100 binary variables are available here, binary variables are one of the decision variables in spreadsheet it has been entered from B56 to B155. Generally, constraints has to be treated in left hand side (LHS) and right hand side (RHS) manner. For binary variables LHS has been entered from D19 to D28 like below

(B56+B66+B76+B86+B $96+\mathrm{B} 106+\mathrm{B} 116+\mathrm{B} 126+\mathrm{B} 136+\mathrm{B} 14$ 6), $(\mathrm{B} 57+\mathrm{B} 67+\mathrm{B} 77+\mathrm{B} 87+\mathrm{B} 97+\mathrm{B} 107+\mathrm{B} 117+\mathrm{B} 127+\mathrm{B} 137+\mathrm{B}$ 147), (B58+B $68+\mathrm{B} 78+\mathrm{B} 88+\mathrm{B} 98+\mathrm{B} 108+\mathrm{B} 118+\mathrm{B} 128+\mathrm{B} 138$ $+\mathrm{B} 148),(\mathrm{B} 59+\mathrm{B} 69+\mathrm{B} 79+\mathrm{B} 89+\mathrm{B} 99+\mathrm{B} 109+\mathrm{B} 119+\mathrm{B} 129+\mathrm{B} 1$ 39+B149), (B60+B70+B80+B90+B100+B110+B120+B130 $+\mathrm{B} 140+\mathrm{B} 150),(\mathrm{B} 61+\mathrm{B} 71+\mathrm{B} 81+\mathrm{B} 91+\mathrm{B} 101+\mathrm{B} 111+\mathrm{B} 121+\mathrm{B}$ $131+\mathrm{B} 141+\mathrm{B} 151),(\mathrm{B} 62+\mathrm{B} 72+\mathrm{B} 82+\mathrm{B} 92+\mathrm{B} 102+\mathrm{B} 112+\mathrm{B} 12$ 2+B132+B142+B152), (B63+B 73+B83+B $93+\mathrm{B} 103+\mathrm{B} 113+$ $\mathrm{B} 123+\mathrm{B} 133+\mathrm{B} 143+\mathrm{B} 153),(\mathrm{B} 64+\mathrm{B} 74+\mathrm{B} 84+\mathrm{B} 94+\mathrm{B} 104+\mathrm{B} 1$ 14+B124+B134+B144+B154), (B65+B75+B85+B95+B105 $+\mathrm{B} 115+\mathrm{B} 125+\mathrm{B} 135+\mathrm{B} 145+\mathrm{B} 155)$ and RHS entered as 1 from F19 to F28.

To mention one machine can do only one job at a time binary constraint has to be entered like below. For this LHS is entered from D30 to D39 as SUM (B56:B65), SUM (B66:B75), SUM (B76:B85), SUM (B86:B95), SUM (B96:B105), SUM (B106:B115) SUM (B1166:B125), SUM (B126:B135), SUM (B136:B1455), SUM (B146:B155) RHS entered from F30 to F39 as 1.

$S_{11} \geq 0$

For this constraint B6 entered as LHS in $\mathrm{K} 7$ and 0 entered as RHS.

$S_{j+1, \mathrm{k},} \geq S_{j k}+\sum_{\mathrm{i}=1}^{\mathrm{n}} \mathrm{x}_{\mathrm{ij}} \mathrm{p}_{\mathrm{ik}}$, foralljexceptnandforallk 


\section{International Journal of Research in Advent Technology, Vol.7, No.4, April 2019 E-ISSN: 2321-9637 \\ Available online at www.ijrat.org}

This constraint is job constraint it emphasizes that the job's starting time has to be higher than the addition of previous job and its processing time. For example, consider the starting time

$\mathrm{S}_{21, \geq \mathrm{S}_{11}+\text { Processing time }}$

For this B11 was entered as a LHS and RHS has to be with the binary variables for this it is $\mathrm{B} 6+(\mathrm{B} 56 * \mathrm{E} 6+\mathrm{B} 66 * \mathrm{E} 7+\mathrm{B} 76 * \mathrm{E} 8+\mathrm{B} 86 * \mathrm{E} 9+\mathrm{B} 96 * \mathrm{E} 10+\mathrm{B} 106$ *E11+B116*E12+B126*E13+B136*E14+B146*E15)

Similarly, all the other constraints has to be entered. $S_{j, \mathrm{k}+1} \geq S_{j k}+\sum_{\mathrm{i}=1}^{\mathrm{n}} \mathrm{x}_{\mathrm{ij}} \mathrm{p}_{\mathrm{ik}}$, foralljandforallkexceptm

This constraint is known as previous machine constraint it more likely to the above constraint in this starting time of the particular job on the current machine has to be higher than the addition of same job's starting time on the previous machine and the processing time. For example $\mathrm{S}_{12, \geq} \mathrm{S}_{11}+$ Processing time

Here LHS is B7 and RHS is $\mathrm{B} 6+(\mathrm{B} 56 * \mathrm{E} 6+\mathrm{B} 66 * \mathrm{E} 7+\mathrm{B} 76 * \mathrm{E} 8+\mathrm{B} 86 * \mathrm{E} 9+\mathrm{B} 96 * \mathrm{E} 10+\mathrm{B} 106 *$ $\mathrm{E} 11+\mathrm{B} 116 * \mathrm{E} 12+\mathrm{B} 126 * \mathrm{E} 13+\mathrm{B} 136 * \mathrm{E} 14+\mathrm{B} 146 * \mathrm{E} 15)$

Similarly, all the constraints has to be entered in the excel spread sheet there will be around 67 constraints which includes both job and machine constraint $C_{j m}=S_{j m}+\sum_{\mathrm{i}=1}^{\mathrm{n}} \mathrm{x}_{\mathrm{ij}} \mathrm{p}_{\mathrm{im}}$, forallj

This is the equation in which completion time for each job can be found by adding starting time of the last job and processing time of the last job it is being entered from P6 to P15 like below,

B9+(B56*H6+B66*H7+B76*H8+B86*H9+B96*H10+B 106 *H11+B116*H12+B126*H13+B136*H14+B146*H15), $\mathrm{B} 14+(\mathrm{B} 57 * \mathrm{H} 6+\mathrm{B} 67 * \mathrm{H} 7+\mathrm{B} 77 * \mathrm{H} 8+\mathrm{B} 87 * \mathrm{H} 9+\mathrm{B} 97 * \mathrm{H} 10+\mathrm{B} 10$ $7 * \mathrm{H} 11+\mathrm{B} 117 * \mathrm{H} 12+\mathrm{B} 127 * \mathrm{H} 13+\mathrm{B} 137 * \mathrm{H} 14+\mathrm{B} 147 * \mathrm{H} 15)$, B19+(B58*H6+B68*H7+B78*H8+B88*H9+B98*H10+B 10 $8 * \mathrm{H} 11+\mathrm{B} 118 * \mathrm{H} 12+\mathrm{B} 128 * \mathrm{H} 13+\mathrm{B} 138 * \mathrm{H} 14+\mathrm{B} 148 * \mathrm{H} 15)$, B24+(B59*H6+B69*H7+B79*H8+B89*H9+B99*H10+B10 $9 * \mathrm{H} 11+\mathrm{B} 119 * \mathrm{H} 12+\mathrm{B} 129 * \mathrm{H} 13+\mathrm{B} 139 * \mathrm{H} 14+\mathrm{B} 149 * \mathrm{H} 15)$, $\mathrm{B} 29+(\mathrm{B} 60 * \mathrm{H} 6+\mathrm{B} 70 * \mathrm{H} 7+\mathrm{B} 80 * \mathrm{H} 8+\mathrm{B} 90 * \mathrm{H} 9+\mathrm{B} 100 * \mathrm{H} 10+\mathrm{B} 1$ $10 * \mathrm{H} 11+\mathrm{B} 120 * \mathrm{H} 12+\mathrm{B} 130 * \mathrm{H} 13+\mathrm{B} 140 * \mathrm{H} 14+\mathrm{B} 150 * \mathrm{H} 15)$, $\mathrm{B} 34+(\mathrm{B} 61 * \mathrm{H} 6+\mathrm{B} 71 * \mathrm{H} 7+\mathrm{B} 81 * \mathrm{H} 8+\mathrm{B} 91 * \mathrm{H} 9+\mathrm{B} 101 * \mathrm{H} 10+\mathrm{B} 1$ $11 * \mathrm{H} 11+\mathrm{B} 121 * \mathrm{H} 12+\mathrm{B} 131 * \mathrm{H} 13+\mathrm{B} 141 * \mathrm{H} 14+\mathrm{B} 151 * \mathrm{H} 15)$, $\mathrm{B} 39+(\mathrm{B} 62 * \mathrm{H} 6+\mathrm{B} 72 * \mathrm{H} 7+\mathrm{B} 82 * \mathrm{H} 8+\mathrm{B} 92 * \mathrm{H} 9+\mathrm{B} 102 * \mathrm{H} 10+\mathrm{B} 1$ $12 * \mathrm{H} 11+\mathrm{B} 122 * \mathrm{H} 12+\mathrm{B} 132 * \mathrm{H} 13+\mathrm{B} 142 * \mathrm{H} 14+\mathrm{B} 152 * \mathrm{H} 15)$, B $44+(\mathrm{B} 63 * \mathrm{H} 6+\mathrm{B} 73 * \mathrm{H} 7+\mathrm{B} 83 * \mathrm{H} 8+\mathrm{B} 93 * \mathrm{H} 9+\mathrm{B} 103 * \mathrm{H} 10+\mathrm{B} 1$ $13 * \mathrm{H} 11+\mathrm{B} 123 * \mathrm{H} 12+\mathrm{B} 133 * \mathrm{H} 13+\mathrm{B} 143 * \mathrm{H} 14+\mathrm{B} 153 * \mathrm{H} 15)$, B49+(B64*H6+B74*H7+B84*H8+B94*H9+B104*H10+B1 $14 * \mathrm{H} 11+\mathrm{B} 124 * \mathrm{H} 12+\mathrm{B} 134 * \mathrm{H} 13+\mathrm{B} 144 * \mathrm{H} 14+\mathrm{B} 154 * \mathrm{H} 15)$, $\mathrm{B} 54+(\mathrm{B} 65 * \mathrm{H} 6+\mathrm{B} 75 * \mathrm{H} 7+\mathrm{B} 85 * \mathrm{H} 8+\mathrm{B} 95 * \mathrm{H} 9+\mathrm{B} 105 * \mathrm{H} 10+\mathrm{B} 1$
$15 * \mathrm{H} 11+\mathrm{B} 125 * \mathrm{H} 12+\mathrm{B} 135 * \mathrm{H} 13+\mathrm{B} 145 * \mathrm{H} 14+\mathrm{B} 155 * \mathrm{H} 15)$.

$\operatorname{Minimize} \sum_{\mathrm{j}=1}^{\mathrm{n}} \max \left(\mathrm{C}_{\mathrm{jm}}\right)$

This is the makespan objective makespan means highest completion time among the jobs or in other words in the job sequence final job's completion time will be considered as makespan. For this P15 is the makespan. The last value of the completion time table is the last job's completion time. It is entered in $\mathrm{H} 3$.

$\operatorname{Minimize} \sum_{\mathrm{j}=1}^{\mathrm{n}} \mathrm{C}_{\mathrm{jm}}$

This is total completion time objective it is nothing but the addition all the completion times here SUM (P6:P15) is entered in E3.

$\operatorname{Minimize} \sum_{j=1}^{n}\left(\frac{\mathrm{P} \alpha * \operatorname{Cjm}}{f \alpha}+\frac{\mathrm{P} \beta * \operatorname{Max}(\mathrm{C} j m)}{f \beta}\right)$

Multi objective combines the two individual objectives into a single objective by using weighted objective method here normalising factors are the highest value of those objectives.

$\mu_{\mathrm{q}}\left(\mathrm{D}_{\mathrm{i}}\right)=\left\{\begin{array}{c}0 \\ \frac{f q-f q H}{f q *-f q H} \mathrm{f}_{\mathrm{q}}{ }^{\mathrm{h}} \leq \mathrm{fq} \leq \mathrm{f}_{\mathrm{q}}{ }^{*} \\ 1\end{array}\right.$

$\mathrm{f}_{\mathrm{q}}{ }_{\mathrm{q}}-$ for this problem it is zero

$\mathrm{f}_{\mathrm{q}_{*}}$ - value

$\mathrm{f}_{\mathrm{q}}$ - The ideal value (highest value)

Here highest value means when the objective has been considered individually to obtain its results those are the highest values for the custom objectives. Purpose of this normalising factors is avoiding high range objective domination over the lower range objective here total completion time is the high range objective it can dominate the makespan objective if the taken weightages are equal. This normalising factors will help to obtain the results in balanced for both objectives even the weightages are equal.

After all, then by clicking add in solver pop up will show up in that decision variables has to be selected from B6 to B155 and then 20 binary constraints and 67 other constraints has to be selected. Finally, simplex algorithm for solving this problem should be selected, the result will be calculated by the solver it will show up.

\section{RESULTS}

To compare the single objective and multi objective problem is going to be solved in two stages in first stage single objectives is going to be selected individually and the results were generated for those objectives. In the second stage multi objective will be solved and the results will be generated.

Multi objective is going to be handled in two 


\section{International Journal of Research in Advent Technology, Vol.7, No.4, April 2019 E-ISSN: 2321-9637 \\ Available online at www.ijrat.org}

ways to show the importance of the normalisers in the multi objective equations. In first way multi objective will be handled with the normalisers and in the another way multi objective will be handled without normalisers.

\section{A. SOLUTION WITH THE NORMALISERS}

This problem has nearly $36,00,000$ possibilities of sequences it took around 160 seconds to solve an objective for the 64 bit $\quad 4 \mathrm{gb}$ ram computer with 2013 version of MS Excel. The generated results are below,

\section{Table 2 Results}

\begin{tabular}{|c|c|c|}
\hline & MAKESPAN & $\begin{array}{c}\text { TCT (Total } \\
\text { Completion Time) }\end{array}$ \\
\hline $\begin{array}{c}\text { Single-Criterion: } \\
\text { Minimize } \\
\text { Makespan }\end{array}$ & 696 & 4776 \\
\hline $\begin{array}{c}\text { Single-Criterion: } \\
\text { Maximize Total } \\
\text { completion time }\end{array}$ & 721 & 4221 \\
\hline $\begin{array}{c}\text { Multi-Criteria: } \\
\text { Optimize Both } \\
\text { Criteria }\end{array}$ & 701 & 4312 \\
\hline
\end{tabular}

Based on the results, there is a $9.7 \%$ greater total completion time with the multi-criteria model compared to the single-criterion makespan model. Also there is a $2.7 \%$ improvement in makespan with the multi-criteria model compared with the single-criterion total completion model.

The multi-criteria model, as would be expected, resulted in makespan and total completion time values in between corresponding makespan and total completion time values in both single-criterion models. This can be visually seen in the bar graph.

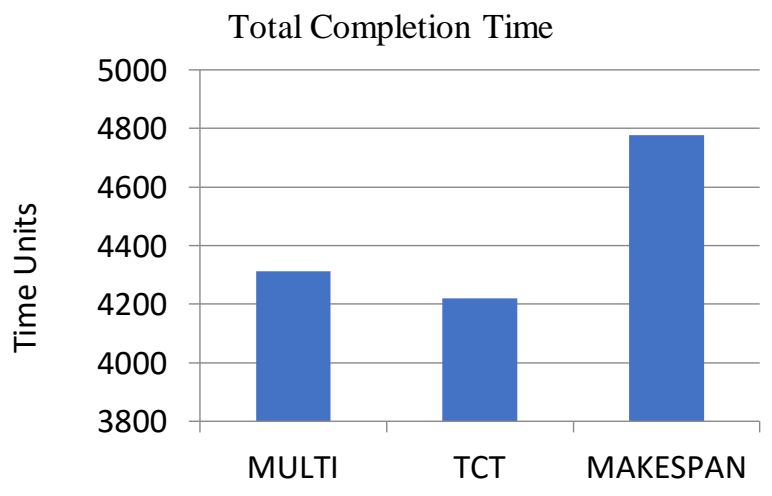

Figure 4 Total Completion Time Results

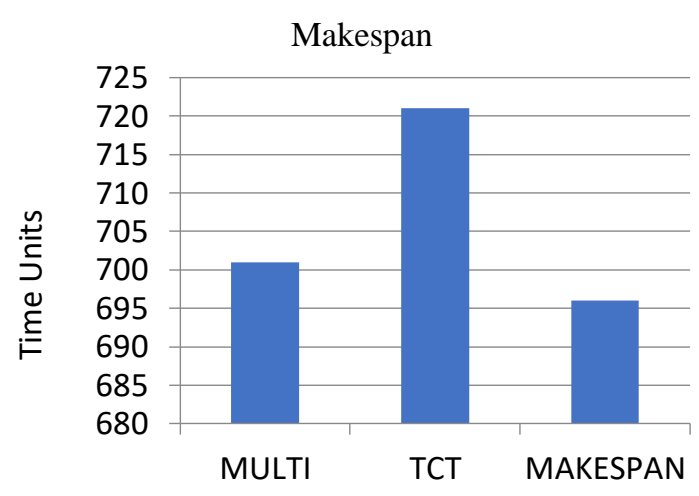

Figure 5 Makespan Results

TCT - Total completion time MULTI - Multi objective

Figure 4 depicts the results for total completion time in that the lowest total completion time 4221 is for the single objective which is for total completion time at the same graph the highest value is for the single objective makespan which is 4776 . Which is far higher around $13 \%$ at the same time we can see multi objective shows 4312 which is $9.7 \%$ lesser than the makespan single objective value And also there is not a much difference between total completion time objective result and the multi objective result there only $2 \%$ difference between them.

Figure 5 represents the results for makespan for all three solved ways in that also corresponding objective results getting lower value multi objective value getting intermediate values and then another single objective value is highest among three. Value for makespan for the single objective is 696 and for single objective the value is 721 which is $3.5 \%$ higher. For multi objective value is 701 there is only $0.7 \%$ difference between the makespan objective result and the multi objective result.

This clearly shows how multi objective is better than the single objective. Importance can be given for these objectives as per the requirements.

\section{B. SOLUTION WITHOUT NORMALISERS}

When the MOFSP equation dealed in this same scenario in which equal weightages given for the objectives without the normalising factors. The domination of the higher range has clearly visible in the bar graph and also in the results

Table 3 Results Without Normalisers

\begin{tabular}{|c|c|c|}
\hline & MAKESPAN & $\begin{array}{c}\text { TCT (Total } \\
\text { Completion } \\
\text { Time) }\end{array}$ \\
\hline $\begin{array}{c}\text { Single-Criterion: } \\
\text { Minimize Makespan }\end{array}$ & 696 & 4776 \\
\hline
\end{tabular}




\section{International Journal of Research in Advent Technology, Vol.7, No.4, April 2019 E-ISSN: 2321-9637 \\ Available online at www.ijrat.org}

\begin{tabular}{|c|c|c|}
\hline $\begin{array}{c}\text { Single-Criterion: } \\
\text { Maximize Total } \\
\text { completion time }\end{array}$ & 721 & 4221 \\
\hline $\begin{array}{c}\text { Multi-Criteria: } \\
\text { Optimize Both Criteria }\end{array}$ & 721 & 4221 \\
\hline
\end{tabular}

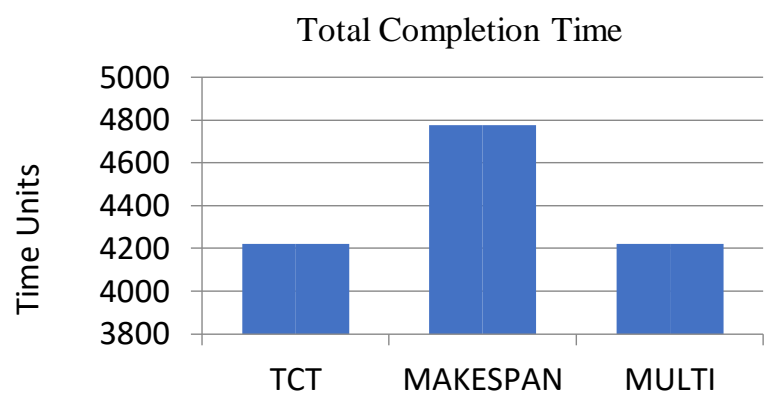
Figure 6 Total Completion Time Results
Without Normaliser

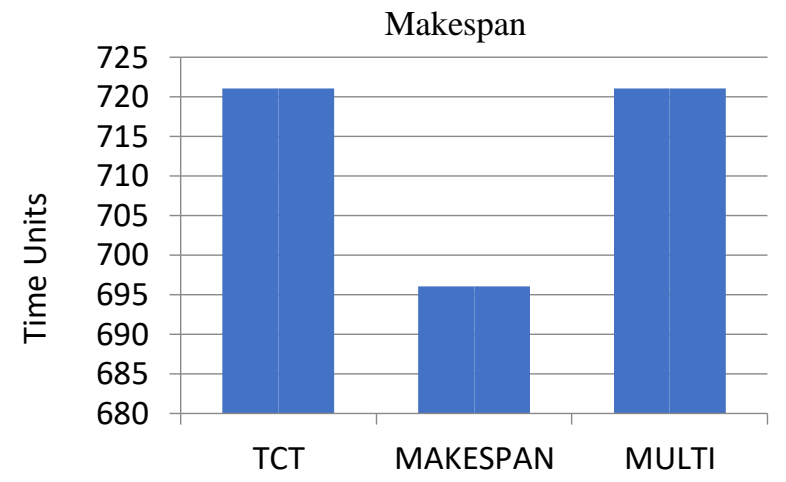

Figure 7 Makespan Results Without Normaliser

Figures 6 and 7 shows clearly the domination of the one objective. Here total completion time dominates the makespan objective because total completion time ranges around 6500 and makespan ranges 900 for this problem. From this importance of normalising factors can be understood.

\section{CONCLUSION}

A Spreadsheet with User-Friendly Interface (SUFI) was developed in Microsoft Excel. Result shows ESUFI can be used to solve small problems. And also created procedure for flow shop scheduling problem in excel worked well. It took around 160 seconds to solve a 10 job 4 machine problem. This solver will be infeasible when the constraints getting more because excel add in solver has a limitation of 100 constraints even though premium solver available for the excel in which 10 times higher problem that can be solved in normal solver can be solved.

Developed MILP for MOFSP works effectively results showed that. It clearly compromised all the objectives as expected. The MILP model is created based on Wilson's model as he insisted there is a limitation for this model. Up to 20 jobs 7 machines can be solved with this model. To solve bigger problems heuristics or meta heuristics has to be created.

The results from the experiment proved that the multi-criteria model performs better than single objective. The importance of the normalising factors to avoid objective domination on another in MOFSP has been showed with the results.

\section{FUTURE WORK}

By using optimisation software the calculation time can be reduced further. To make highly effective user interface an application programming interface API can be used. To solve bigger problems heuristics can be developed for MOFSP it can be compared with this exact method results to check its efficiencies. The subjective scheduling and the theoretical scheduling difference can be analysed by addressing industries and also economic analysis also can be conducted and how much cost can be save by scheduling also can be analysed.

\section{REFERENCES}

[1] Dhingra, "Multi objective floe shop scheduling using meta heuristics" kurkshetra 136119 Haryana, 2010.

[2] MinellaRuben Ruiz, "A Review and Evaluation of Multi-Objective Algorithms for the Flow Shop Scheduling Problem" Informs journal of computing pp. 451-471, 2008.

[3] Rony Peterson da Rocha1, Mauro Antonio Silva Sa Ravagnani, Cid Marcos GoncalvesAndrade and Paulo Roberto, "Use of excel worksheets with user-friendly interface to minimize the makespan in a permutation flow shop production" Actascientiarum Technology, pp.453-461, 2014.

[4] Ronconi and birgin, "Mixed-integer programming models for flow shop scheduling problems minimizing the total earliness and tardiness", Just-in-Time Systems, pp. 91-105, 2012.

[5] Simarokni, "Optimisation of industrial shop scheduling using simulation and fuzzy logic" Edmonton alberta, Spring, 2010.

[6] Taillard, "Benchmarks for basic scheduling problems" European journal of operations research, pp.278-285, 1993.

[7] Wilson, "Alternative formulations of a flow-shop scheduling problem", Journal of the Operational Research Society 40, pp. 395-399,1989.

[8] Yi Sun \&Chaoyong Zhang \& Liang Gao\&Xiaojuan Wang, "Multi-objective optimization algorithms for flow shop scheduling problem: a review and prospects" International journal of advance manufacturing technology, 2010. 